\title{
PREFACE
}

\section{Effective Treatment of Childhood Stuttering}

As part of the continuing education program in Seminars in Speech and Language, and Thieme's ongoing surveys of the Seminars readership, we continue to ask Seminars subscribers for input on the topics that they wish to see covered by the journal. Our most recent feedback has been quite emphatic in asking for increased coverage of diagnostic and intervention information about stuttering and fluency disorders. Despite varied terminology in their comments, readers were twice as likely to request more coverage in this area than any other single speech or language disorder or cross-disciplinary topic. Thus, I am particularly pleased to be able to offer Seminars readers a second issue to follow up our well-received first presentation (Semin Speech Lang, vol. 23, no. 3, 2002) of topics germane to stuttering therapy, with special emphasis on successfully meeting the challenges posed by working with school-aged children.

I am very fortunate to have been able to enlist the able and enthusiastic Scott Yaruss to shepherd these two issues to publication. Professor Yaruss has collected a wide number of concisely written articles that address potential options for use by therapists, particularly those in the traditional school setting who work with children who stutter. This issue focuses on specific topics that include information technology in stuttering, multicultural concerns in stuttering assessment and treatment, self-therapy techniques including self-regulation, how to achieve generalization of therapy objectives, establishment and maintenance of family-teacher partnerships in treatment, the use of fluency special- ists, and how to plan and conduct professional in-services.

Because more and more of the families of children who stutter now seek information from the Internet, it is both timely and imperative that clinicians be able to steer clients to the best available information, and at the same time educating them about the emerging pitfalls of the basically unregulated and highly trafficked information highway. As a rapidly increasing number of school-aged children reflect wide diversity in linguistic and cultural backgrounds, clinicians must be ever able to respond appropriately to caseload management that varies from the "mainstream American" profiles they may have been exposed to in clinical training. Generalization of therapy objectives outside the clinical (school) setting has arguably been the largest challenge facing any SLP treating children's communicative disorders. In addition to a broadly focused tutorial offering options for facilitating such generalizations of therapy goals, this issue also offers an introduction to one of a number of "self-therapy" techniques that, when taught and utilized correctly, can effectively help a person who stutters achieve and maintain fluency. True therapeutic progress, as the articles in this issue repeatedly note, is achieved when children can essentially become their own therapists, understanding the nature of their disorder, comfortably employing facilitative skills and techniques, and responding positively to unexpected challenges.

All children receiving services for communicative impairment under IDEA do ideally have

Facing the Challenge of Treating Stuttering in the Schools, Part 2: Selecting Goals and Strategies for Success. Editors in Chief, Nancy Helm-Estabrooks, Sc.D., and Nan Bernstein Ratner, Ed.D.; Guest Editor, J. Scott Yaruss, Ph.D. Seminars in Speech and Language, volume 24, number 1, 2003. ${ }^{1}$ Department of Hearing and Speech Sciences, University of Maryland, College Park, Maryland. Copyright (C) 2003 by Thieme Medical Publishers, Inc., 333 Seventh Avenue, New York, NY 10001, USA. Tel: +1(212) 584-4662. 0734-0478,p;2003,24;01,001,002,ftx,en;ss100149a. 
IEPs that involve their parents and teachers, but this mandate often falls far from ideal satisfaction in everyday practice. This issue of Seminars offers approaches to establishing a strong and productive family-teacher-clinician partnership that benefits the child's progress in therapy. Finally, in related articles, the often-remarked shortage of qualified therapists with interest and expertise in the treatment of childhood stuttering is addressed with two helpful and increasingly useful options: the use of consultative recognized fluency specialists, and the construction and implementation of in-service training experiences to broaden knowledge among school-based personnel on appropriate management of the child who stutters.
In short, for the many thoughtful and responsive readers who have been requesting more information on the treatment of fluency disorders, this issue should provide good grist for thought and action. I think you will enjoy this issue and find it immensely useful in your clinical practice. As usual, I look forward to hearing from you regarding your opinions of this issue and additional topics you would like to see covered in future issues.

Nan Bernstein Ratner, Ed.D. Co-Editor in Chief ${ }^{1}$ 